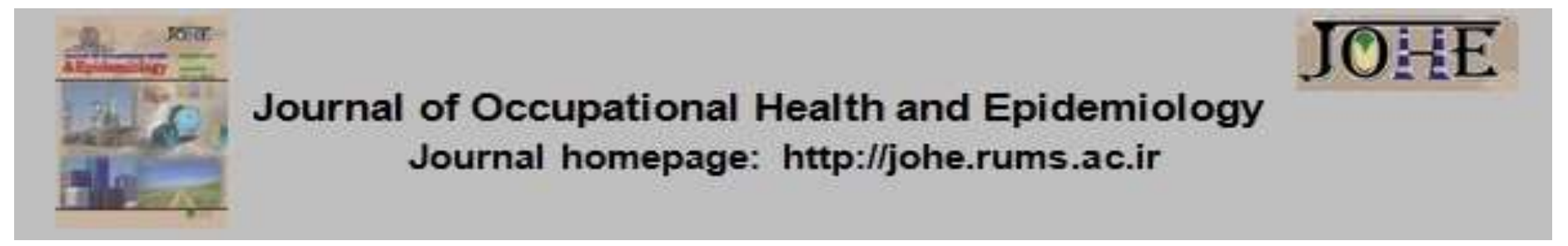

\title{
The role of personality traits in predicting family functioning and quality of life among nurses, Shiraz, Iran 2017-2018
}

\author{
Laleh Ajeli Lahiji ${ }^{*}$, Mohammad Ali Besharat ${ }^{2}$ \\ 1- MA of Psychology, Department of Psychology, Islamic Azad University, Shiraz, Iran. \\ 2- Professor of Clinical Psychology, Department of Psychology, University of Tehran, Tehran, Iran.
}

Citation: Ajeli Lahiji L, Besharat MA. The role of personality traits in predicting family
functioning and quality of life among nurses, Shiraz, Iran 2017-2018. JOHE 2019;
8(2):82-7.

\section{Article Info}

${ }^{*}$ Corresponding author:

Laleh Ajeli Lahiji,

E-mail:

lalehlahiji@gmail.com

\section{Article history}

Received: Nov, 2018

Accepted: Apr, 2019

10.29252/johe.8.2.82

\section{Print ISSN: 2251-8096} Online ISSN: 2252-0902

Peer review under responsibility of Journal of Occupational Health and Epidemiology

\begin{abstract}
Background: Quality of life and family functioning is affected by several psychological factors, of which personality traits can be noted as the most important ones. This research aimed to investigate the role of personality traits in predicting family functioning and quality of life among nurses in the city of Shiraz from 2017 to 2018.

Materials and Methods: This descriptive-correlational study was performed on all married nurses in Shiraz who were selected using convenience sampling method. The data collection tools included family functioning, quality of life, and personality dimensions' questionnaires. Data were analyzed in SPSS (version 23) software using simple correlation coefficients and multiple regressions.

Results: The results showed that $26 \%$ of the variance in family functioning of nurses is explained by the components of neuroticism, flexibility, extroversion, and $24 \%$ of the variance in quality of life is explained by the components of personality traits. In addition, $20 \%$ of the variance in the quality of life of nurses is explained by the flexibility components. It should be noted that the level of significance in this study was set at $0.05(\alpha=0.05)$.

Conclusion: Based on the results of this study, since personality traits play an important role in the quality of life and family functioning of nurses in different dimensions. it is necessary to make plans for improving the quality of life and family functioning of nurses. It is also recommended that mental health be evaluated periodically to improve QOL and family functioning of nurses.
\end{abstract}

Keywords: Personality, Quality of Life, Nurses, Iran

\section{Introduction}

One of the most obvious issues in every organization, especially in hospitals, for the executives is the issue of quality of life for staff, especially the quality of life of nurses, who are responsible for maintaining and improving the health and quality of life of patients (1). Nursing is one of the most stressful occupations. Factors that cause stress for nurses include high demands at work, hard work, exposure to acute emergency lifethreatening or unstable patients, inadequate ratio of nurses to patients, and lack of the required equipment. Therefore, nursing is among the occupations that causes a level of stress and job stress (2). Nurses constitute the largest group of human resources in healthcare systems of almost all countries. They also play a significant role in community health promotion (3). Nurses are responsible for maintaining and improving the health and quality of life of patients. Therefore, it is important to assess the quality of life and family functioning of nurses in order to improve it (4).

Based on the five-factor personality model, personality comprises five traits, including neuroticism, extraversion, agreeableness, conscientiousness, and openness to experience (5). According to researches, personality traits determine the interactions of individuals over time and in different cultures (6). Personality can be an 
important factor in the conditions of stress and give rise to different responses (7). Given the importance of family in creating a healthy society, family functioning and the type of family relationship can create a healthy and dynamic family. In this regard, researchers argue that personality traits can play a role in family functioning (8-10). Regarding personality dimensions, the highest score in the field of extroversion is gained by having high performance and a healthy family. Poor personality traits are associated with lower family performance. The results of this study emphasize the importance of personality traits in family functioning (11).

A high quality of life and having successful marital relationships have not only a significant influence on happiness among individuals but also unlimited benefits for society (12). Therefore, the life and health of the family depend on its most important part. This means that the quality of life and of the marital relationship and the strength and dynamism of the society and working situation depend on the stability and balance of the family (12). Unterrainer, Ladenhauf and Moazedi et al. (2010) investigated the relationship between quality of life and other factors such as personality, health, and environment and obtained a significant relationship among these components (13).

Sheikholeslami and Mohammadi (2015) quoted by Fletcher also investigated the relationship between personality traits and quality of life and found that people who were socially happy, more sympathetic about others, and more connected to themselves and the community had a higher quality of life (14). The findings showed a significant negative relationship between neuroticism and the nurses' quality of life. Furthermore, there was a positive correlation between extroversion, openness, agreeableness, conscientiousness, and their quality of life. Among the predictor variables, neuroticism and openness could significantly predict nurses' quality of life (15).

In the other study, personality traits, including extraversion, agreeableness, and conscientiousness, had a positive relationship with quality of life dimensions; there was a negative relationship between neuroticism and quality of life dimensions, and there was no significant relationship between openness to experience and quality of life dimensions (16).

So far, research has not has not paid due attention to the role of personality traits in predicting family functioning and quality of life among nurses. Therefore, this study aimed to investigate the role of personality traits in predicting family functioning and quality of life among nurses.

\section{Materials and Methods}

This descriptive study is of a correlational type. The statistical population of the present study was all male and female nurses in Shiraz in 2017-18. The participants in the study included 100 nurses (50 men and 50 women) who were randomly selected based on Morgan table.

In the research field, researchers participated actively to prevent accidental responses and to answer any potential questions asked by the subjects.

The entry and exit criteria of the research included not using psychiatric drugs, being married, and signing the informed consent from. The participant's refusal to cooperate and incomplete questionnaires were the criteria for exclusion from the study. The tools were the following three questionnaires:

Family Performance Measurement Questionnaire (FAD): FAD has been developed based on the McMaster theory and by Epstein, Baldwin, and Bishop (17). This questionnaire had 60 items and was scored from 1 to 4 based on the Likert scale. The validity of the questionnaires has been appropriately evaluated within and outside Iran. In the Iranian version of the questionnaire, the Cronbach's alpha factor was obtained to be 0.94 for all the instruments, and the subscales were also defined as issue solving (0.86), communications (0.87), roles $(0.87)$, emotional responsiveness (0.81), emotional inclusion (0.89), the general family functioning (0.82) (17). In Yousefi's study, the validity and reliability of the test were also examined. Cronbach's alpha and Split-half for 60 items of the questionnaire were obtained to be 0.83 and 0.82 , respectively. The convergent and divergent validity of the questionnaire with the communication patterns questionnaire harnessed the center questionnaire for the subscales of emotional response and merged with the other, obtaining the values $0.46,0.36,-0.41$, and -0.43 , respectively (18). In the study by Mohammadi and Molkkhosravi, Cronbach's alpha for the entire scale was 0.90 , and the test-retest coefficient was 0.82 (19). In this research, Cronbach's alpha, for the family functioning questionnaire was 0.86 .

Quality of Life Questionnaire: Wier \& Sherbourne (1992) developed this self-report questionnaire which is mainly used to assess the quality of life and health (20). This questionnaire has 36 phrases and 8 areas of physical functioning, physical role, bodily pain, general health, vitality, social functioning, and emotional role and mental health. It provides two general measures of performance and assesses the overall score of the SF component, physical pain, and general health. The subject's score in each of these areas varies from 0 to 100, and a higher score 
indicates a higher quality of life. The validity and reliability of this questionnaire was confirmed in the Iranian population $(21,22)$, and the internal consistency coefficients of the eight subscales were reported between 0.70 and 0.85 , and their testretest coefficients at intervals of one week range from 0.43 to 0.79 . In addition, this questionnaire can distinguish healthy people from all patients (22). Cronbach's alpha for the quality of life questionnaire in this research was 0.93 .

The Five-factor Personality Test (NEO-FFi): McCrae and Costa (23) developed the Five-Factor Personality Test (NEO-FFi) and showed that the correlation of the five subscales of the short form the long form are 0.77 to 0.92 , respectively. The shortened form of five personality traits assessment questionnaire, called NEO-FFI, which is a 60 -item questionnaire to assess five basic personality traits, namely, neuroticism, extraversion, openness to experience, agreeableness, and conscientiousness (each with 12 questions) was used to collect data. The questionnaire measures five aspects of personality. Extreme stability, extroversion or introversion, pleasure, flexibility and accountability, and conscientiousness are not among the general subscales of this test. A score was obtained, each of which related to a personality factor. In Iran, its validity and reliability were confirmed by content validity, and Cronbach alpha was over 0.70 (24). In this research, Cronbach's alpha for the different subscales were as follows: psychic component 0.87 , flexibility 0.83 , extroversion 0.72 , conscientiousness of 0.91 , agreement 96.0.

The data were analyzed using descriptive and inferential tests. Version 23 of the SPSS software was used to analyze the collected data through descriptive statistics, simple correlation coefficients, and multiple regressions. Furthermore, the significance level was set at 0.05 .

\section{Results}

As can be seen in the table below, the majority of respondents with a frequency of $45 \%$ ( 45 people) were in the age group 30-40 years old. Also, most respondents with a frequency of $58(58)$ were in the group who had been married for 5-10 years, with the highest percentages.

Table 1: Demographic variables

\begin{tabular}{|c|c|c|c|}
\hline Variable & Group & Frequency & Percentage \\
\hline \multirow{2}{*}{ Gender } & Female & 50 & 50 \\
\hline & Male & 50 & 50 \\
\hline \multirow{3}{*}{ Duration of marriage } & Under 5 & 20 & 20 \\
\hline & $5-10$ & 58 & 58 \\
\hline & 10 to upper & 22 & 22 \\
\hline \multirow{3}{*}{ Age } & 25 to 30 & 45 & 45 \\
\hline & 30 to 40 & 45 & 45 \\
\hline & 41 and higher & 10 & 10 \\
\hline
\end{tabular}

The mean and SD of neuroticism $(25.77 \pm 3.09)$, flexibility (33.74 \pm 4.16$)$, extroversion ( $36.91 \pm 3.76$ ), conscientiousness (33.62 \pm 4.05$)$, agreeableness (32.72 \pm 7.31 ), family functioning (133.72 \pm 9.27$)$, and quality of life of nurses (83.02 \pm 8.24$)$ are shown.

In Table 2, the correlation coefficient between neuroticism, flexibility, extroversion, conscientiousness, and consistency with nurses' family functioning are shown using a Pearson domain, respectively. According to these results, it can be concluded that there is a negative relationship between neuroticism and family functioning of nurses, and there is a positive and significant relationship between flexibility, extroversion, and the nurses' family functioning, but there is not a significant relationship between agreeableness and the nurses' family functioning. In addition, the correlation coefficient between neuroticism, flexibility, extroversion, conscientiousness, and adaptability with the nurses' quality of life was obtained using a one-way test. The Pearson amplitude for the subjects was obtained, respectively. According to these results, there is a significant negative relationship between flexibility and quality of life. Nevertheless, there is not a meaningful relationship between quality of life and the nurses' neuroticism. There is a significant relationship between the components of personality traits with the nurses' family functioning. 
Table2: Correlation between personality characteristic components with family functioning and quality of life among nurses in Shiraz, 2017-2018

\begin{tabular}{lcccc}
\hline \multirow{2}{*}{ Independent variable } & \multicolumn{4}{c}{ Dependent variable } \\
\cline { 2 - 5 } & \multicolumn{2}{c}{ Family function } & \multicolumn{2}{c}{ Quality of life } \\
\cline { 2 - 5 } & $\mathrm{R}$ & $\mathrm{P}$ & $\mathrm{R}$ & $\mathrm{P}$ \\
\hline Neurotic & $\star \star 0.026-$ & $\mathrm{p}=0.001$ & $\mathrm{p}=04-$ & $\mathrm{p}=065$ \\
\hline Flexibility & $\star \star 0.22$ & $\mathrm{p}=0.002$ & $\star \star 0.29$ & $\mathrm{p}=0.003$ \\
\hline Extroversion & $\star 0.21$ & $\mathrm{p}=0.003$ & 0.02 & $\mathrm{p}=0.082$ \\
\hline Conscientiousness & $\star 0.17$ & $\mathrm{p}=0.004$ & $\star 0.19$ & $\mathrm{p}=0.004$ \\
\hline Agreeableness & 0.02 & $\mathrm{p}=0.083$ & 0.08 & $\mathrm{p}=0.042$ \\
\hline
\end{tabular}

The significance of correlation coefficients was statistically significant $\star \star ~(p<0.01)$, * $(p<0.05)$.

As shown in Table 3, according to the results of the regression, the method of entering components of personality traits can predict family functioning. $R$ and $\mathrm{R} 2$ were 0.49 and 0.24 , and $0.24 \%$ of the variance of nurses' family functioning is explained by the components of personality traits.

Table 3: Results of regression analysis of predictive variables with family functioning by input method for subjects among nurses in Shiraz, 2017-2018

\begin{tabular}{|c|c|c|c|c|c|}
\hline Criteria variable & $\begin{array}{c}\text { Indexes } \\
\text { predicting variable }\end{array}$ & MR & $\mathbf{R}^{2}$ & FP & $\frac{\text { Coefficient regression }}{1}$ \\
\hline \multirow{5}{*}{$\begin{array}{c}\text { Family } \\
\text { functioning }\end{array}$} & Neurotic & \multirow{5}{*}{0.49} & \multirow{5}{*}{0.24} & \multirow{5}{*}{$\begin{array}{c}3.59 \\
p<0.001\end{array}$} & $\begin{array}{c}\beta=0.26- \\
\mathrm{t}=2.76- \\
\mathrm{P}=0.007\end{array}$ \\
\hline & Flexibility & & & & $\begin{array}{c}\beta=0.13 \\
\mathrm{t}=1.33 \\
\mathrm{P}=0.04\end{array}$ \\
\hline & Extroversion & & & & $\begin{array}{c}\beta=0.24 \\
\mathrm{t}=2.68 \\
\mathrm{P}=0.009\end{array}$ \\
\hline & Conscientiousness & & & & $\begin{array}{l}\beta=0.24 \\
2.56 \mathrm{t}= \\
0.01 \mathrm{P}=\end{array}$ \\
\hline & Agreeableness & & & & $\begin{array}{c}\beta=0.08 \\
\mathrm{t}=0.85 \\
\mathrm{P}=0.39\end{array}$ \\
\hline
\end{tabular}

As can be seen in Table 4, according to the regression results, the method of entering the components of personality traits can predict the quality of life. $\mathrm{R}$ and $\mathrm{R} 2$ are 0.49 and 0.24 respectively, that is, $24 \%$ of the variance of nurses' quality of life is explained by the components of personality traits.

Table 4: Results of regression analysis of predictive variables with family functioning by input method for subjects among nurses in Shiraz, 2017-2018

\begin{tabular}{|c|c|c|c|c|c|}
\hline $\begin{array}{l}\text { Criteria } \\
\text { variable }\end{array}$ & $\begin{array}{c}\text { Indexes } \\
\text { predicting variable }\end{array}$ & MR & $\mathbf{R}^{2}$ & FP & $\frac{\text { Coefficient regression }}{1}$ \\
\hline \multirow{5}{*}{$\begin{array}{l}\text { Quality of } \\
\text { life }\end{array}$} & Neurotic & \multirow{5}{*}{0.49} & \multirow{5}{*}{0.24} & \multirow{5}{*}{$\begin{array}{c}3.59 \\
p<0.001\end{array}$} & $\begin{array}{c}\beta=-0.01 \\
\mathrm{t}=-0.19 \\
\mathrm{P}=0.85\end{array}$ \\
\hline & Flexibility & & & & $\begin{array}{c}\beta=0.24 \\
\mathrm{t}=2.48 \\
\mathrm{P}=0.01\end{array}$ \\
\hline & Extroversion & & & & $\begin{array}{c}\beta=0.007 \\
\mathrm{t}=0.07 \\
\mathrm{P}=0.94\end{array}$ \\
\hline & Conscientiousness & & & & $\begin{array}{c}\beta=0.017 \\
\mathrm{t}=1.72 \\
\mathrm{P}=0.08\end{array}$ \\
\hline & Agreeableness & & & & $\begin{array}{c}\beta=0.005 \\
t=0.04 \\
P=0.39\end{array}$ \\
\hline
\end{tabular}




\section{Discussion}

Due to the nature of their profession, nurses are generally in close contact with many problems, which affect their family functioning and their quality of life. Given this psychological distress on nurses, this study aimed to investigate the role of personality traits in predicting family functioning and quality of life among nurses.

According to the results, there is a negative relationship between neuroticism and family functioning of nurses and a significant positive relationship between flexibility, extroversion, and nurses' family functioning, but there is not a significant relationship between agreeableness and nurses' family functioning. This research is not in line with the findings of earlier studies, because family functioning has not been studied in nurses so far. Family functioning including behavioral control, roles, emotional responsiveness, maybe emotional involvement is very important to reduce workrelated stress (25).

Family functioning is related to the mental health of family members, and there is a significant relationship between poor family performance, and physical symptoms, anxiety, sleep disturbance, depression, and the social functioning disorder. On the other hand, families with good performance solve their problems at different levels and at different times. They avoid drying out or fossilizing interactive processes in the family. In such families, difference is considered as a positive issue, because it strengthens problem-solving strategies (26). There is no study about family functioning of nurses' performance, and maybe the present study is the first study of this kind.

The results showed that neuroticism has a significant negative relationship and extroversion, openness, agreeableness, and conscientiousness have a significant positive relationship with the nurses' quality of life, which is in accordance with many previous studies $(15,16)$. Bakhshayesh's findings (2013) revealed a significant negative correlation between neuroticism among the staff of health centers (27). To explain this finding, it should be said that genetic predisposition prepares people with a neurotic personality to be depressed, anxious, and ready to lose their health. At the same time, they are subjected to more negative and stress-inducing events because of their negative views (16). Neuroticism can also predict irrational beliefs (28).

On the other hand, extraversion is accompanied with positive emotions, so extrovert people see the events more positively and, as a result, have a better general health (16). Based on the results of (29) study, since personality traits play an important role in various dimensions of quality of life of nurses, it is expected that admission of nurses in this field will be done based on their personality traits. There is no doubt that the staff in a health center are one of the major factors that determine the quality of the medical care provided for patients; therefore, it is essential to have careful plans for improving the quality of life of medical personnel.

This study has limitations such as limited sample, the convenience sampling method used in the study, and findings that just refer to nurses of Shiraz; it is hoped that future research uses larger samples and other sampling methods to improve the quality of research. As a suggestion, the variables of this research can be studied with other groups, such as nursing student couples, divorced people, and other paired partners.

\section{Conclusion}

According to the results of the analysis, flexibility, extroversion, openness, and conscientiousness have a positive relationship and neuroticism has a negative relationship with nurses' family functioning. Nevertheless, flexibility, extroversion, openness, and conscientiousness have a positive relationship and neuroticism has a negative relationship with nurses' quality of life. Therefore, these variables (flexibility, extroversion, openness, and conscientiousness) can be good predictors of psychological well-being due to express emotions and can have an effective role in improving the quality of life of nurses and family functioning. There is no doubt that the staff of health centers are one of the major factors that determine the quality of the medical care provided for patients; therefore, it is important and valuable to have careful plans for improving the quality of life of medical personnel.

\section{Acknowledgement}

The authors are grateful to all the nurses who were fully accountable to us and to all the people who cooperated with us in this research.

\section{Conflict of interest: None declared.}

\section{References}

1. Kieft RA, de Brouwer BB, Francke AL, Delnoij DM. How nurses and their work environment affect patient experiences of the quality of care: a qualitative study. BMC Health Serv Res 2014; 14:249.

2. Pour S. Exploring psychological stressors with regard to the moderating role of perceived social support in female nurses of Ghaem hospital emergency department of Mashhad City. Iran Occupational Health 2013; 10(4):65-74. 
3. Fallahnejad Z, Hassanzadeh R. The relationship between nurses' personality type and job satisfaction. Journal of Nursing and Midwifery Sciences 2015; 2(2):42-7

4. Hatamipour Kh, Hoveida F, Rahimaghaee F, Babaeiamiri N, Ashoori J. The Nurses' Quality of Life Based on Burnout, Perceived Social Support and Psychological Hardiness. Journal of Research Development in Nursing \& Midwifery 2017; 14(1):22-8.

5. Golestanbagh N, Amani R, Neamatpour S, Haghighizadeh $\mathrm{MH}$. Investigation of Correlation between Personality Traits and Dietary Habits in Female Students. Qom University of Medical Sciemces Journal 2016; 10(3):55-63

6. Miri M, Besharat MA, Asadi M, Shahyad Sh. The Relationship between Dimensions of Personality and Sexual Desire in Females and Males. Procedia Soc Behav Sci 2011; 15:823-7.

7. Ajeli Lahiji L, Besharat MA. Prediction of family function and life quality based on the attachment styles of couples. Semi-annual Journal Family Pathology, Counseling \& Enrichment 2018; 3(2):119-38.

8. Khosravi S, Hamidi M. Predicting the family function based on personality traits and religious attitudes. Paper presented at: The National Congress of Prayer and Mental Health; 2016 Nov 9-10; University of Tehran, Tehran.

9. Kobee AL. Family function, aggression, and psychopathic personality traits in college students. [MSc thesis]. San Marcos, Texas, United States: Texas State University; 2015.

10. Jafari Poor H, Borji M, Borji M, Moslemi A. The Relationship between Spiritual Well-being and Quality of Life and Optimism on the Staff of Arak University of Medical Sciences 2012. Health, Spirituality and Medical Ethics 2016; 3(2):8-15

11. Perveen A, Kee P, Bt Hamzah H, Binti Mohd Sa'ad F, Binti Mohmed Darussalam NS. Relationship between Personality Traits and Perception of Family Functioning among Unwed Pregnant Teenagers. International Journal of Humanities, Social Sciences and Education 2017; 4(9):40-5

12. Rahmani K, Tofiqi B, Bahmani MR. Comparison of marital satisfaction, quality of life, psychological well-being and psychological resilience of education sector and non-education sector employed women and unemployed housewives in Bushehr city. The Journal of New Advances in Behavioral Science 2017; 2(11):3854.

13. Unterrainer HF, Ladenhauf $\mathrm{KH}$, Moazedi ML, Wallner-liebmann SJ, Fink A. Dimensions of Religious / Spiritual Well-Being and their relation to Personality and Psychological WellBeing. Pers Individ Dif 2010; 49(3):192-7.

14. Sheykholeslami A, Azarniyoor S, Mohammadi N. Prediction of Quality of Life Based on Sexual Attitude and Knowledge, and Personality Traits in Married Women. Journal of Health and Care 2015; 17(3):260-9.
15. Alipour Hamze Kandi N, Zeinali A. Relationship between Personality Characteristics, Internal Locus of Control, Psychological Hardiness and Nurses' Quality of Life. Journal of Research Development in Nursing \& Midwifery 2017; 14(1):8-15.

16. Seyedoshohadaee M, Hakimi MH, Mardani M, Baqaee $H$. The Relationship between Personality Traits and General Health of Nursing Students. Journal of Client-Centered Nursing Care 2017; 3(1):11-8.

17. Mirzaei Alavijeh M, Nasirzadeh M, Eslami AA, Sharifirad Gh, Hasanzadeh A. Influence of Family Function about Youth Dependence to Synthetic Drugs. Iranian Journal of Health Education and Health Promotion 2013; 1(2):1930.

18. Yoosefi N. An Investigation of the Psychometric Properties of the McMaster Clinical Rating Scale [MCRS]. Training Measurement 2012; 3(7):85112

19. Zadeh Mohammadi A, Malek Khosravi Gh. The preliminary study of psychometric and reliability of Family Assessment Device. Journal of Family Research 2006; 2(5):69-89.

20. Ware JE Jr, Sherbourne CD. The MOS 36 -item short-form health survey (SF-36). I. Conceptual framework and item selection. Med Care 1992; 30(6):473-83.

21. Montazeri A, Goshtasebi A, Vahdaninia $M$, Gandek B. The Short Form Health Survey (SF36): translation and validation study of the Iranian version. Qual Life Res 2005; 14(3):875-82.

22. Asghari Moghaddam M, Faghehi S. Validity of the SF-36 Health Survey Questionnaire in Two Iranian Samples. Clinical Psychology \& Personality 2003; 1(1):1-10.

23. Hogan R, Johnson J, Briggs S. Handbook of Personality Psychology. 1st ed. Cambridge, Massachusetts, United States: Academic Press; 1997. P.825-47.

24. Zarbakhsh M, Taghavi Dinani $P$, Rahmani $M$. The relationship between sexual self-esteem and all its components with marital satisfaction in athletic women of Tehran. European Online Journal of Natural and Social Sciences 2013; 2(2):200-6.

25. Zanganeh B, Kaboudi M, Ashtarian H, Kaboudi $B$. The comparison of family function based on the McMaster model in fertile and infertile women. J Med Life 2015; 8(Spec Iss 4):196-202.

26. Golpich Z, Soleimanyan AA, Darudi H. A Study of the Relationships between Family Functioning and Psychological Hardiness among Parents with Exceptional Children and Normal Children. Iranian Rehabilitation Journal 2012; 10(1):56-61.

27. Bakhshayesh AR. The Relationship between Personality Types and General Health with Job Satisfaction of Yazd Health Center Staffs. Journal of Payavard Salamat 2013; 7(1):42-55.

28. Nasri S, Heydari Bafghi R, Jararh J. Personality characteristics, irrational beliefs and communication skills as Predictors school 
counselors' job performance. Biannual Journal of Applied Counseling 2017; 7(1):27-46.

29. Seyedallshohadaee M, Mardani M, Haggani $H$, Abbasi M, Hakimi MH. The Correlation between
Personality Traits and Quality of Life in Nursing Students of Qom University of Medical Sciences, 2016, Iran. Qom University of Medical Sciences Journal 2017; 10(11):71-8. 